\title{
An epidemiological study of the health of Sri Lankan tea plantation workers associated with long term
} exposure to paraquat

\author{
N Senanayake, G Gurunathan, T B Hart, P Amerasinghe, M Babapulle, S B Ellapola, \\ M Udupihille, V Basanayake
}

\begin{abstract}
Pulmonary function tests (FVC, $\mathrm{FEV}_{1}, \mathrm{FEV}_{1}$ I FVC\%, TLCO, single breath CO diffusion), chest $x$ ray film, renal function (serum creatinine and blood urea nitrogen), liver function (serum alanine aminotransferase, aspartate transferase, and alkaline phosphatase, bilirubin, total protein, and albumin), a haematological screen (haemoglobin and packed cell volume), and a general clinical examination were performed on 85 paraquat spraymen (mean spraying time 12 years) and on two control groups (76 factory workers and 79 general workers) frequency matched for age and years of occupational service. All the subjects were men. There were no clinically important differences in any of the measurements made between the study group and the two control groups. In particular the results of the lung function tests, appropriate for paraquat toxicity of the study group, were similar to those of the control groups. The same was true of blood tests for liver and kidney function. The incidence of skin damage, nose bleeds, and nail damage in the study group was slightly higher than in the control groups but lower than the incidence reported for paraquat workers in previous studies. The results of this study confirmed that long term spraying of paraquat, at the concentrations used, produced no adverse health effects, in particular no lung
\end{abstract}

Faculty of Medicine, University of Peradeniya, Sri Lanka

N Senanayake, $M$ Babapulle, $M$ Udupihille, V Basanayake Janatha Estates Development Board, Dickoya, Hatton District, Sri Lanka

G Gurunathan

ICI Agrochemicals, Fernhurst, Surrey, UK (Present address: ICI Pharmaceuticals, Alderley Park, Macclesfield, Cheshire, UK)

T B Hart

General Hospital (teaching), Kandy, Sri Lanka

P Amerasinghe, S B Ellapola, $M$ Babapulle damage, attributable to the occupational use of the herbicide.

(British Journal of Industrial Medicine 1993;50:257-263)

Paraquat (1, $1^{1}$-dimethyl-4,4'-bipyridylium) dichloride is a broad spectrum contact herbicide and desiccant first introduced in 1961 and now in widespread use in over 130 countries throughout the world. Several formulations are available, the most common of which is gramoxone, an aqueous solution containing $200 \mathrm{~g}$ paraquat ion per litre. Before application the concentrated formulation is diluted at least 40 times and then usually between 100 and 250 times to form a spray solution $(0 \cdot 2-0 \cdot 08 \%)$. The concentrated formulation, gramoxone, can damage the skin by caustic action on prolonged or repeated contact but the diluted spray strength solution is only mildly irritating and paraquat is poorly absorbed from intact skin.

Paraquat can cause serious and often fatal lung injury after accidental or deliberate ingestion of the concentrate, but during almost 30 years of widespread agricultural use it has not been associated with serious occupational health injury or fatality. ${ }^{2-4}$ Nevertheless concern has been expressed that workers exposed to paraquat over long periods might be at risk, especially of lung injury.

Because of the greater exposure of operators using knapsack sprayers with the minimum of protective clothing, Swan ${ }^{5}$ carried out a study of the health of Malaysian rubber plantation workers spraying paraquat in this way and also measured systemic absorption of the herbicide. He concluded that ordinary care in personal hygiene is sufficient to prevent any hazard from surface injury or from systemic absorption. This study involved a short term (several weeks) exposure. In a later epidemiological study Howard et $a l^{6}$ examined the health of 27 Malaysian plantation workers exposed to paraquat (mean spraying time 5.3 years) in comparison with similar numbers of two control groups. The results showed no significant differences as a consequence of occupational exposure to paraquat. 
The difficulty of carrying out retrospective epidemiological studies, similar to that described by Howard et al, ${ }^{6}$ mainly reflects the difficulty in identifying groups of workers who have been exposed only to paraquat for long periods of time. Most agricultural workers are exposed to several different pesticides in any one season and movement of workers between jobs can be frequent.

The identification of a large group of Sri Lankan tea plantation workers who had sprayed mainly paraquat for long periods provided another opportunity to investigate the health of such chronically exposed personnel who had used paraquat under different operating conditions from those investigated by Howard $e t a l .{ }^{6}$ In an attempt to determine whether such long term spraying (minimum five years and average 12 years) had any measurable health effects, the spraymen were compared with roughly equivalent numbers of two control groups of factory and general workers who had not been exposed to paraquat during their work.

\section{Methods}

SITE OF INVESTIGATIONS

All workers came from estates of the Janatha Estates Development Board (JEDB), which is based in Dickoya, Sri Lanka. Estates were located in Hatton District about 1300 metres above sea level. All health examinations were performed by hospital staff at the General Hospital (teaching) and Faculty of Medicine, Peradeniya, near Kandy. Groups of 10-30 workers were transported from the estates to Peradeniya, a distance of about $48 \mathrm{~km}$, by bus each day. Translation from the main language (Tamil) of the workers to that of the hospital staff (Sinhalese) was provided by medical staff of JEDB.

\section{POPULATION}

All workers selected were men from six Janatha estates. Each worker was categorised into one of three groups according to occupation.

\section{Control group 1}

Tea factory workers. Their duties included all aspects of tea processing, once the freshly picked leaves arrived at the factory. As the above ground part of the tea plant, notably the leaves, contain no residues of paraquat, these workers would have no occupational exposure to paraquat.

\section{Control group 2}

General estate workers whose duties involved wall and road maintenance, mechanical land clearance, and transport. They do not spray paraquat and were therefore used as a second non-exposed control group.

\section{Study group}

These workers fell into two subgroups: (1) spraymen, the larger subgroup, who apply the diluted product through their own backpack sprayers; each is responsible for maintaining and cleaning his own sprayer. (2) Mixer-loaders, who dilute the concentrated product (gramoxone) with water in a large drum before dispensing it for application by the spraymen. For convenience the two subgroups who used paraquat are referred to collectively as spraymen.

About 80 workers per group were frequency matched for age and duration of service, with a minimum of five years of using paraquat (study group) or with an established previous long service as a factory or general worker. Workers were excluded from the survey if they had any illness for which there was evidence that it was not work related. One worker from control group 1 (factory workers) was withdrawn from the study since he was found to have had pulmonary tuberculosis in 1983 .

Each worker's history and identification was recorded-namely, (1) medical history, (2) social history including smoking and drinking habits, (3) occupational history including type of occupation, duration of service, protective measures used, and, if applicable, exposure to pesticides other than paraquat. Estate records were retrospectively examined to verify information supplied by the workers. Because workers often had similar names, identification was also based on age, registration number, address, and estate on which each worked.

Table 1 shows the mean age, height, weight, and years of service for each of the three groups. From the workers' histories, the average length of time that spraymen may have been using paraquat was 12 years, but some may have used the product for as long as 20 years.

All spraymen had used paraquat for a minimum of five years, but 11 factory workers (control group 1) and three general workers (control group 2) had not been in their respective occupations for a minimum of five years. Service years were not recorded for a further eight general workers. Nevertheless, the groups were well matched for age, height, weight, and years of service. Those workers with less than five years of service are therefore unlikely to affect the outcome of the study and have been included in the analyses.

Table 2 shows the number of days spent spraying as recorded in estate records. In many cases the worker claimed to have used paraquat over longer periods than estate records were kept.

None of the workers in the control groups or the study group admitted exposure to paraquat during their normal working day.

Nearly all the spraymen did, however, admit to exposure to pesticides other than paraquat, outside of their work. In most cases, the exposure was 
Table 1 Age, height, weight, and years of service of the worker groups

\begin{tabular}{|c|c|c|c|c|c|c|}
\hline & \multicolumn{2}{|c|}{$\begin{array}{l}\text { Factory workrers } \\
\text { (control group } 1 ; n=76)\end{array}$} & \multicolumn{2}{|c|}{$\begin{array}{l}\text { General workers } \\
\text { (control group 2; } n=79 \text { ) }\end{array}$} & \multicolumn{2}{|l|}{$\begin{array}{l}\text { Spraymen } \\
(n=85)\end{array}$} \\
\hline & Mean (SD) & Range & Mean ( $S D$ ) & Range & Mean (SD) & Range \\
\hline $\begin{array}{l}\text { Age (y) } \\
\text { Height (m) } \\
\text { Weight }(\mathrm{kg}) \\
\text { Service }(\mathrm{y})\end{array}$ & $\begin{array}{cl}34 \cdot 4 & (9 \cdot 1) \\
1 \cdot 61 & (0 \cdot 06) \\
48 \cdot 1 & (5 \cdot 2) \\
13 \cdot 2 & (9 \cdot 2)\end{array}$ & $\begin{array}{l}17-53 \\
1 \cdot 46-1 \cdot 74 \\
34-63 \\
1-40\end{array}$ & $\begin{array}{cl}34.0 & (7 \cdot 3) \\
1.62 & (0 \cdot 05) \\
49.4 \quad(4 \cdot 8) \\
16.5 \quad(7 \cdot 3)\end{array}$ & $\begin{array}{l}21-52 \\
1 \cdot 46-1 \cdot 81 \\
38-62 \\
4-37\end{array}$ & $\begin{array}{c}32 \cdot 8(6 \cdot 6) \\
1.62(0.06) \\
48 \cdot 5 \quad(5 \cdot 2) \\
12 \cdot 0 \quad(7 \cdot 2)\end{array}$ & $\begin{array}{l}22-55 \\
1 \cdot 49-1 \cdot 79 \\
35-59 \\
5-20\end{array}$ \\
\hline
\end{tabular}

infrequent and resulted from use on their smallholdings.

Of those workers categorised as spraymen, eight were mixer-loaders, 70 were involved in spraying, and seven did both jobs. None of these workers wore protective clothing; all were barefoot and wore either a sarong or shorts and a short sleeved shirt.

\section{HEALTH EXAMINATIONS}

Observer bias during health examinations was minimised by ensuring that the hospital staff involved did not have access to details concerning the workers' occupational history.

\section{General health}

Each worker underwent a general clinical examination, which included the following parameters: (1) resting pulse, and blood pressure (systolic and diastolic), using a sphygmomanometer and arm cuff; (2) examination of the respiratory system; (3) examination of the nervous system; (4) examination of the skin.

\section{Blood tests}

Blood tests were carried out for haemoglobin concentration and packed cell volume, renal function (urea and creatinine concentration), and liver function (alkaline phosphatase, aspartate, and alanine transferase activities and bilirubin, total protein and albumin concentrations).

\section{Lung function tests}

A Morgan Transfer test model B (P K Morgan Ltd, Chatham, Kent) was used to measure ventilatory and alveolar function. The performance of the instrument met international standards. ${ }^{7}$ Maximum expiratory flow volume (MEFV) curves were used to assess airway function and a minimum of three technically satisfactory curves were recorded. To ensure repeatability, values for forced vital capacity (FVC) from these curves agreed to $\pm 5 \%$. The highest FVC was used to identify the volume points for maximum expiratory flow when $50 \%$ and $25 \%$ of FVC remained to be expired $\left(\mathrm{MEF}_{50 \%}\right.$ and $\mathrm{MEF}_{25 \%}$ respectively). The three curves were superimposed at total lung capacity (TLC; onset of expiration) and the highest values of $\mathrm{MEF}_{50 \%}$ and $\mathrm{MEF}_{25 \%}$ recorded. $^{7}$ Also, the highest value of peak expiratory flow (PEF) was recorded. Volume time spirograms were recorded simultaneously and used to calculate forced expiratory volume in one second $\left(\mathrm{FEV}_{1}\right)$ and forced mid-expiratory flow (FMEF). Carbon monoxide transfer factor (TLCO) was used to measure alveolar function. One single breath manoeuvre, by the method of $\operatorname{Cotes}^{8}$ was performed by each subject. The results of the lung function tests were calculated manually by a single observer.

\section{Chest $x$ ray films}

Posterior anterior views only were taken unless clinical examination indicated that lateral views were also required.

\section{STATISTICAL METHODS}

Analysis of covariance was used to compare the three groups of workers. For the purpose of statistical analysis, measurements were divided into three groups: (1) tests of pulmonary function; (2)

Table 2 Days spent spraying by the study group (from estate records)

\begin{tabular}{|c|c|c|c|c|c|c|c|}
\hline \multirow[b]{2}{*}{ Estate } & \multirow[b]{2}{*}{ No } & \multicolumn{2}{|l|}{ Total days } & \multicolumn{2}{|c|}{ Days since 1 Jan 1982} & \multicolumn{2}{|c|}{ Average No of days per year } \\
\hline & & Mean (SD) & Range & $\operatorname{Mean}(S D)$ & Range & Mean (SD) & Range \\
\hline
\end{tabular}

*1 January 1981 to 31 March 1987.

+1 January 1977 to 31 March 1987. 
haematological and biochemical parameters; blood pressure and pulse rate.

A linear model taking into account smoking history, age, interaction between age and smoking history, height, weight, and occupation was fitted to the pulmonary function data. A similar model was fitted to haematological and biochemical data, but replacing the age smoking history interaction term with alcohol intake.

A model taking into account smoking history, age, obesity, and occupation group was fitted to the blood pressure and pulse rate data. Obesity was measured by the Quetelet index $=$ weight $/$ height ${ }^{2}\left(\mathrm{~kg} / \mathrm{m}^{2}\right)$.

Smoking was not found to be an important explanatory factor for haematological and biochemical data, but differences existed between estates for these parameters. Another linear model was, therefore, fitted taking into account estate, occupation, interaction between occupation and estate, age and alcohol intake. For certain biochemical parameters a logarithmic transformation gave closer agreement with assumption of a normally distributed error term.

The effect of spraying was investigated by taking the residuals for the study group from the above models and examining their relation with different durations of exposure to paraquat.

Four separate terms were used to measure exposure to paraquat as determined from estate records-namely, (1) the total number of spraying days, (2) the total number of spraying days in the past five years, and (3) and (4) the logarithms of (1) and (2). To calculate the logarithms, each total was increased by one day to ensure that no worker sprayed zero days. Average yearly totals were also considered as possible measures of exposure, but were found to be highly correlated with the total number of spraying days. The means calculated were least squares means, ${ }^{9}$ which correct for any imbalance in the number of workers in the different categories broken down by factors present in the analysis of covariance model. The means were calculated with covariates taking their average values in the study.

\section{Results}

Individual medical and other data for each worker are available in the records of the study; summaries only are presented here.

\section{MEDICAL HISTORY}

The medical histories of the three groups of workers were evaluated especially with regard to incidences of asthma, bronchitis, and skin disease. Apart from the absence of asthma among the spraymen, the groups had similar medical histories.

Current symptoms of the workers were recorded.
Skin damage was more common in the spraymen (20 cases: $23.6 \%$ of the total number of spraymen) compared with either factory workers (nine cases: $11 \cdot 8 \%$ ) or general workers (12 cases: $15 \cdot 2 \%)$. Nail damage was not reported by factory workers, but the spraymen and general workers reported a similar incidence of this complaint. Nose bleeds were an infrequent occurrence, none being reported by general workers, one case by the factory workers, and three cases by the study group (all spraymen). There were no other differences between groups for current symptoms.

\section{SOCIAL HISTORY}

Smoking history and alcohol consumption was compared for the different groups of workers. The proportion of non-smokers and non-drinkers in control group 2 (general workers) was lower than in the other two groups, although alcohol consumption in the spraymen was, on average, higher in those spraymen who drank compared with the other groups.

\section{PULMONARY FUNCTION TESTS}

Table 3 summarises the mean and standard error of the mean (SEM) values for the results of the pulmonary function tests standardised for age, height, and weight. No statistically significant or clinically important differences were found between groups for any of the parameters measured. In particular, mean TLCO, which can be affected by paraquat toxicity in humans, was no different in the spraymen compared with either of the other two groups.

Individual data for pulmonary function tests are listed in the study records and the normal group $(n=240)$ ranges of the pulmonary function values in this study were also calculated. Separate ranges were calculated for workers aged $<35$ years and aged 35 years or older. One worker in control group 1 had an abnormal value for $\mathrm{FEV}_{1} / \mathrm{FVC}(52 \cdot 78)$, but all other lung function measurements in this subject were within the normal range. Another worker in control group 2 had abnormal values for $\mathrm{FEV}_{1} / \mathrm{FVC}$ and $\mathrm{FEV}_{1}$. There were no workers in the study group with lung function values outside the normal range.

From the estate record data, regressions of the residuals from the pulmonary function analyses of variance showed no significant associations between lung function values and duration of exposure, with one exception. This was a positive association between logarithm of duration of exposure over the past five years and $F E V_{1} / F V C$, implying that a greater duration of exposure was associated with an increase in this value.

\section{CHEST X RAY FILM}

Nine workers in each of the control groups and five spraymen showed abnormal findings on chest $x$ ray 
Table 3 Pulmonary function tests standardised for age, height and weight

\begin{tabular}{|c|c|c|c|c|c|c|c|c|c|}
\hline & $\begin{array}{l}F V C(l) \\
\text { Mean } \\
(S E M)\end{array}$ & $\begin{array}{l}F E V_{1}(l) \\
\text { Mean } \\
(S E M)\end{array}$ & $\begin{array}{l}F E V_{1} / F V C(\%) \\
\text { Mean } \\
(S E M)\end{array}$ & $\begin{array}{l}\operatorname{PEF}(l / s) \\
\text { Mean } \\
(\text { SEM) }\end{array}$ & $\begin{array}{l}F E F_{25-7 s}(l / s) \\
\text { Mean } \\
(S E M)\end{array}$ & $\begin{array}{l}M E F_{s 0 \%}(l / s) \\
\text { Mean } \\
(S E M)\end{array}$ & $\begin{array}{l}M E F_{25 \%}(l / s) \\
\text { Mean } \\
(S E M)\end{array}$ & $\begin{array}{l}T L \\
(\operatorname{mmol} C O / \min / k P a) \\
\text { Mean } \\
(S E M)\end{array}$ & $\begin{array}{l}V_{A}(l) \\
\text { Mean } \\
(S E M)\end{array}$ \\
\hline \multirow{3}{*}{$\begin{array}{l}\text { Control } \\
\text { group } 1 \\
\text { Control } \\
\text { group } 2 \\
\text { Study } \\
\text { group }\end{array}$} & $3.42(0.06)$ & $2.76(0.06)$ & $80 \cdot 67(1 \cdot 10)$ & $8.04(0.24)$ & $3 \cdot 20(0 \cdot 15)$ & $3.89(0.20)$ & $1.40(0.08)$ & $10 \cdot 17(0.21)$ & $4.46(0.08)$ \\
\hline & $3.49(0.06)$ & $2.82(0.06)$ & $80.98(1.03)$ & $8 \cdot 36(0.23)$ & $3.15(0.15)$ & $3.87(0.18)$ & $1.39(0.07)$ & $10 \cdot 41(0 \cdot 19)$ & $4.52(0.08)$ \\
\hline & $3.48(0.06)$ & $2.82(0.05)$ & $80.89(0.98)$ & $8.35(0.21)$ & $3 \cdot 18(0 \cdot 14)$ & $3.94(0.17)$ & $1.34(0.07)$ & $10.47(0.19)$ & $4.56(0.08)$ \\
\hline
\end{tabular}

film examination. Apart from one general worker with chronic chest $x$ ray film changes, none of the abnormalities were associated with abnormal clinical findings. Also, none of the pulmonary function tests were grossly abnormal and most fell within the normal ranges.

\section{BLOOD HAEMATOLOGY AND BIOCHEMISTRY}

Individual data for blood haematology and biochemical values are listed in the study records and the normal group $(n=240)$ ranges for these values were also recorded.

\section{Blood haematology}

Table 4 summarises the values for haemoglobin and packed cell volume for each group of workers.

There were no clinically significant differences between groups, although mean values were significantly lower $(\mathrm{p}<0.05)$ in control group 1 (factory workers) compared with control group 2 (general workers).

Three workers in control group 1 had haemoglobin values below the range for all workers $(7 \cdot 6 \mathrm{~g} / \mathrm{dl}$; $9.6 \mathrm{~g} / \mathrm{dl}$, and $9.5 \mathrm{~g} / \mathrm{dl}$ respectively). In one of those workers the low haemoglobin was associated with a low packed cell volume $(28 \%)$. One worker in the study group also had abnormally low haemoglobin $(8.0 \mathrm{~g} / \mathrm{dl})$ and packed cell volume values $(33 \%)$. No worker in control group 2 had abnormally low values. There was no association between duration of exposure (from estate records) and haematology values.

\section{Blood biochemistry}

Although some of the differences in mean values for blood biochemistry for each group of workers

Table 4 Haematological parameters for each group of workers

\begin{tabular}{lll}
\hline & $\begin{array}{l}\text { Haemoglobin }(g / \text { dl) } \\
\text { Mean }(\text { SEM) }\end{array}$ & $\begin{array}{l}\text { Packed cell volume (\%) } \\
\text { mean }(\text { SEM) }\end{array}$ \\
\hline Factory workers & $14.28 \star(0 \cdot 16)$ & $44.87^{\star}(0.48)$ \\
General workers & $14.84(0 \cdot 16)$ & $46.35(0.50)$ \\
Spraymen & $14.50(0 \cdot 15)$ & $45.37(0.46)$ \\
\hline
\end{tabular}

${ }^{\star} \mathrm{p}<0.05$, significantly different from general workers. achieved statistical significance-for example, alkaline phosphatase activity in control group 2 was significantly ( $<<0.050$ ) higher than in the other two groups-none of the differences were clinically important. In particular, values assessing liver and renal function were not clinically different between groups. Two workers in control group 2 had blood urea values $(7.6 \mathrm{mmol} / 1$ in both cases) above the normal range for all workers, but in neither case was the serum creatinine concentration abnormal.

One worker in control group 1 had an alkaline phosphatase value of $317 \mathrm{U} / \mathrm{l}$, which is above the normal range of all workers, but no other abnormal values for liver function. Another worker in control group 1 had a serum aspartate transferase activity of $31 \mathrm{U} / \mathrm{l}$; above the normal range, but not clinically important.

One worker in control group 1 had an albumin concentration of $36.8 \mathrm{~g} / \mathrm{l}$, which is below the normal range, but had no other abnormal biochemical values. Another worker in control group 2 had an abnormally low total protein concentration of 63.0 $\mathrm{g} / \mathrm{l}$. Neither worker's protein values were clinically abnormal.

No worker in the study group had an abnormal blood biochemistry, although serum aspartate transferase activity was positively associated with the total number of spraying days and the number of days spent spraying over the past five years. The associations were statistically significant $(p<0.05$ for total days: $p<0.01$ for days in the past five years) with regression coefficients of $3.2 \times 10^{-4}$ and $5.4 \times 10^{-4}$ for total days and days over the past five years respectively.

\section{CLINICAL EXAMINATION}

Resting heart rate and blood pressure (systolic and diastolic)

There were no differences in either mean heart rate or blood pressures between groups.

\section{Chest examination}

The numbers of workers who exhibited abnormal physical signs included nine in control group 2 (all related to airways obstruction-rhonchi), seven in control group 1 (six related to airways obstruction- 
rhonchi; one with a history of tuberculosis and three in the study group (all related to airways obstruction-rhonchi). Six out of the nine workers in control group 2 had associated respiratory symptoms (mainly cough), four out of the seven in control group 1 had associated symptoms (cough) and none of the study group had associated symptoms. All workers except two (one control group 1, one study group) had a history of smoking.

\section{Other clinical findings}

Individual clinical findings and a summary of the frequency and type of abnormal clinical findings for each group are listed in the study records. The following abnormalities were noted: (1) One worker in control group 2 (general workers) had an irregular pulse. (2) One sprayman had bilateral abnormal plantar reflexes and increased muscle tone in the right upper limb. Otherwise results of examination of the nervous system were normal for all groups. In particular there was no evidence of any extra pyramidal disorder in any worker suggestive of a Parkinson-like disease.

\section{Discussion}

The toxicity of paraquat in humans has usually been reported in the context of acute poisoning, mainly from ingestion of the product with suicidal intent. Under these circumstances the main target organs for toxicity are the lungs, the liver, and the kidneys. It is clear, however, from reviewing poisoning cases that the lung is the most sensitive organ. ${ }^{10}$

The presence of time and energy dependent accumulation of paraquat into lung cells explains the organ's sensitivity. ${ }^{11}$ Thus as the plasma paraquat concentration falls, the rate of uptake into lung cells will also fall. A plasma concentration will eventually be reached when the rate of uptake of paraquat will equal its removal from lung cells and under these conditions lung accumulation will not occur. For animal models-for example, rats-this concentration has been calculated to be between 0.2 and $0.5 \mu \mathrm{g} / \mathrm{ml} .{ }^{12}$ Because laboratory studies have shown that human lung behaves similarly towards paraquat as does rat lung ${ }^{13}$ it is reasonable to conclude that plasma concentrations of paraquat of less than $0.2 \mu \mathrm{g} / \mathrm{ml}$ will not lead to accumulation in the lungs and damage in humans.

Chester et al ${ }^{14}$ have measured dermal exposure and absorption of paraquat in a group of workers representative of the study group examined in this study. Although the spraymen were exposed dermally to paraquat (about $72 \mathrm{mg} /$ day) no paraquat was detected in their urine. As the limit of detection of paraquat in urine by their method was about $0.03 \mu \mathrm{g} / \mathrm{ml}$ and concentrations in blood are always below urine concentrations, it follows that paraquat concentrations in blood were always well below $0.03 \mu \mathrm{g} / \mathrm{ml}$ and consequently no lung accumulation or damage should occur-even on long term exposure.

It is concordant therefore to find that the results of this study show no clinical, radiological, or laboratory evidence of lung damage attributable to long term exposure to paraquat. Furthermore, there was evidence to show that the general health, including liver and kidney function of the study group (spraymen and mixer loaders) was similar to that of the two control groups. Although there was an association between increased serum aspartate transferase activity and increased duration of exposure in the study group, the rate of increase was so low as to be clinically insignificant. Furthermore, at the time of examination, none of the study group had clinically abnormal values of serum aspartate transferase activity.

There was also no evidence of a Parkinson-like disease as evidenced from neurological assessment contradicting earlier claims that exposure to paraquat may result in this disease..$^{15}$ These results, although relating to different conditions of use of paraquat, support those reported in Malaysian workers by Howard et al. ${ }^{6}$

The incidence of some reversible adverse effects in the study group was reported to be in excess of the two control groups. These included headache, nose bleeds, and skin and nail damage. The incidence of headache in all groups was high $(15 \cdot 8 \%$ to $21 \cdot 2 \%)$ and as this is such a common symptom, differences between groups are unlikely to be clinically important.

Nose bleeds occurred in three $(3.6 \%)$ workers in the study group, none of whom were mixer-loaders, and in one worker of one control group. Nail damage occurred in nine workers $(10.5 \%)$ of the study group. The incidence of this finding was the same as in control group 2 but much lower than reported in sugar cane workers in Trinidad (53 out of 285 workers) by Hearn and Keir. ${ }^{16}$ Skin damage, when reported, consisted of cracks on the heels or soles of the feet and was probably related to abrasion rather than exposure to paraquat. Nevertheless, the incidence of skin damage in the study group $(23.6 \%)$ was lower than that reported in Malaysian workers by Swan (six out of 12 workers). ${ }^{5}$

The low incidence of skin and nail damage in the exposed workers (study group) in this study compared with the incidence reported in other publications can be explained by at least two factors: firstly, although the Sri Lankan workers wore very little work clothing and no protective clothing, their personal hygiene was excellent. They tended to wash themselves frequently in running water throughout the working day. Secondly, the spray concentration used $(0.04-0.07 \% \mathrm{w} / \mathrm{v}$ paraquat ion) was dilute and 
as such non-irritant. These two factors, together with paraquat's poor penetration through skin $^{17} 18$ may also explain why absorption was low in these workers (non-detectable in urine) despite measurable dermal exposure. ${ }^{14}$

The evidence from this study indicates that the long term occupational use of paraquat (on average 12 years) is not associated with any adverse health effects in workers exposed to the product. In particular, lung damage and abnormalities of kidney or liver function are not associated with long term use of paraquat.

We express sincere thanks for the untiring work of Ajanta Pereira of CIC Colombo. In addition thanks are due to the hospital staff of the University of Peradeniya and the medical assistants of the Janatha Estates. Lastly thanks are due to John Tomenson and Sue Mortenson of ICI Epidemiology Unit at Alderley Park for their advice and work on the statistical analysis.

1 World Health Organisation. Paraquat and diquat Geneva: WHO 1984. IPCS environmental health criteria 39.

2 Howard JK. Paraquat: a review of worker exposure in normal usage. J Soc Occup Med 1990;30:6-11.

3 Garnier R, Conso F, Efthymiou ML. Paraquat toxicity in an occupational setting. Medico-Legal Toxicology 1980;23:22737.

4 Hart TB. Paraquat: a review of safety in agricultural and horticultural use. Human Toxicology 1987;6:13-8.

5 Swan AAB. Exposure of spray operators to paraquat. $\mathrm{Br} J$ Ind Med 1969;26:322-9.

6 Howard JK, Sabapathy NN, Whitehead AP. A study of the health of Malaysian plantation workers with particular reference to paraquat spraymen. Br J Ind Med 1981;38:110-6.

7 Quanjer PH. Standard lung function testing. Bulletin de Physiopathologie Respiratoire 1983;19:suppl 5.

8 Cotes JE. Lung function: assessment and application in medicine. 4th ed. Oxford: Blackwell Scientific Publications, 1979.

9 Searle SR, Speed FH, Milliken GA. Population marginal means in the linear model: an alternative to least square means. The American Statistician 1980;34:216-21.

10 Vale JA, Meredith TJ, Buckley BM. Paraquat poisoning: clinical features and immediate general management. Human Toxicology 1987;6:41-7.

11 Rose MS, Smith LL, Wyatt I. Evidence for the energy dependent accumulation of paraquat into rat lung. Nature 1974;252:314-5.

12 Smith LL, Wright A, Wyatt I, Rose MS. Effective treatment for paraquat poisoning in rats and its relevance to treatment of paraquat poisoning in man. $B M J 1974 ; 4: 569-71$.

13 Rose MS, Lock EA, Smith LL, Wyatt I. Paraquat accumulation: tissue and species specificity. Biochem Pharmacol 1976;25: 419-23.

14 Chester G, Gurunathan G, Jones N, Woollen BH. Occupational exposure of Sri Lankan tea plantation workers to paraquat. 1992 (in press).

15 Lewin R. Parkinson's disease-An environmental cause? Science 1985;229:257-9.

16 Hearn CED, Keir W. Nail damage in spray operators exposed to paraquat. Br J Ind Med 1971;28:399-403.

17 Walker M, Dugard PH, Scott RC. Absorption through human and animal skins: in vitro comparison. Acta Pharma Centica Suecica 1983;20:52-3.

18 Wester RC, Maibach HI, Bucks DAW, Aufrere MB. In vitro percutaneous absorption of paraquat from hand, leg and forearm of humans. J Toxicol Environ Health 1984;14:759-62.

Accepted 8 June 1992 